\title{
Tensile Behaviour of Aluminium Oxide and Zirconium Dibromide Reinforced Aluminum Alloy 6063 Surface Composites
}

\author{
R. Raja, Sabitha Jannet, Allen Varughese, Lijin George, Sumanth Ratna
}

\begin{abstract}
The present study aims to investigate the Aluminium oxide and Zirconium diboride particles reinforced aluminum surface composites fabricated using Friction Stir Processing (FSP). Al-6063 was used as base-metal and Aluminium oxide and Zirconium diboride were used as reinforcement media. Al 6063 is used for architectural fabrication; window and door frames, pipe and tubing, and aluminium furniture Tensile strength specimens were prepared as per ASTM-E8 Standard. Tensile strength were found using UTM. Then it is found that that the tensile strength of the composite decreases as the volume percentage of the particles added for the reinforcement increases in the composites.
\end{abstract}

Keywords: FSP, Aluminium oxide and Zirconium diboride particles, Tensile Strength

\section{INTRODUCTION}

Aluminium (Al) and its alloys (Al-Si-Mg) are extensively adopted in structural, automobile, aerospace, and marine applications. Especially, Aluminum Alloy (AA) 6063 is the widely selected material for medium strength application because of its formability, and weldability. Among them, particulate reinforced AMCs (PRAMCs) have been extensively investigated in recent years due to their excellent and isotropic mechanical properties, easy fabrication and low cost . In general, various types of ceramic particles (like carbides, oxides, borides and nitrides) with high strength, elastic modulus and wear resistance are introduced into $\mathrm{Al}$ matrix as reinforcements to fabricate the PRAMCs. In this work $75 \%$ aluminium nitride and $25 \%$ boron nitride hybrid mixture was dispersed onto surface of copper metal matrix by fricrion stir processing. An appreciable increase in tensile strength was noted with an increase in wear properties with increase in volume of the hybrid reinforcement volume percentage.[1]A single pass FSP was carried out to reinforce $\mathrm{TiC}$ particles in

Revised Manuscript Received on February 05, 2020.

* Correspondence Author

R. Raja, Assistant Professor, Department of Mechanical, Karunya Institute of Technology and Sciences, Coimbatore, TamilNadu, India.

Sabitha jannet*, Assistant Professor, Department of Mechanical, Karunya Institute of Technology and Sciences, Coimbatore, TamilNadu, India. E-mail: sabithajannet@gmail.com

Allen Varughese, Assistant Professor, Department of Mechanical, Karunya Institute of Technology and Sciences, Coimbatore, TamilNadu, India.

Lijin George, Assistant Professor, Department of Mechanical, Karunya Institute of Technology and Sciences, Coimbatore, TamilNadu, India.

Sumanth Ratna, Assistant Professor, Department of Mechanical, Karunya Institute of Technology and Sciences, Coimbatore, TamilNadu, India.

(C) The Authors. Published by Blue Eyes Intelligence Engineering and Sciences Publication (BEIESP). This is an open access article under the CC BY-NC-ND license (http://creativecommons.org/licenses/by-nc-nd/4.0/)
AA6083.The process paranmetrs were set at $1200 \mathrm{rpm}$ rotational speed, traverse speed of $60 \mathrm{~mm} / \mathrm{min}$ and axial load of $10 \mathrm{KN}$.The composite with various volume percentage were fabricated.The TiC particle significantly influenced the area of the composite, grain size, Ultimate Tensile strength and wear properties .[2]Friction stir processing was used as a secondary process to study the microstructural changes in the Al3 Fe Aluminium Matrix Composite cast. The sever deformation increased the dislocations and microstructural changes lead to the improved tensile properties in the cast.[3]This work focuses on the reinforcement of quartz withAA6063.The synthesised composites were of volume percentage varying from 0 to $18 \%$ with an increment of $6 \%$.The micro hardness and wear properties improved due to the better dispersion of the quartz particles[4].This work reports the reinforcement of Fly Ash with aluminium as matrix with volume percentage varying from 0 to 16 percent. The dispersion of the Fly Ash particle was uniform in the stir zone irrespective of the location and thus improved mechanical properties were obtained.[5]Ceramic particles were reinforced on copper matrix by FSP. The process parameters were set at $1000 \mathrm{rpm}$ rotational speed, traverse speed of $40 \mathrm{~mm} / \mathrm{min}$ and $10 \mathrm{KN}$ axial load. The stir zone, grain size, distribution and the mechanical properties did not change significantly but remained in short range.[6]

\section{EXPERIMENTAL DETAILS}

TABLE I. CHEMICAL COMPOSITION OF AL 6063

\begin{tabular}{llllllllll}
\hline Elements $\mathrm{Si}$ & $\mathrm{Fe}$ & $\mathrm{Cu}$ & $\mathrm{Mn}$ & $\mathrm{Mg}$ & $\mathrm{Cr}$ & $\mathrm{Zn}$ & $\mathrm{Ti}$ & $\mathrm{Al}$ & others \\
\hline
\end{tabular}

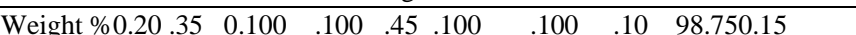

Table-1 shows the chemical composition of Aluminium 6063.it gives the idea of other elements weight percentage in the given metal.

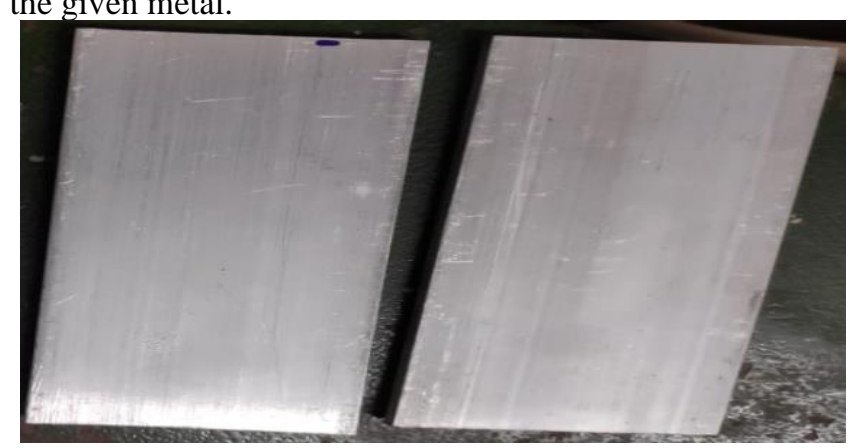

Fig. 1. Al6063 Metal Plate

Figure 1indicates that aluminium 6063 metal plates.AA 6063 is the base metal which is using for the FSP processing. 
The plates were cut in the dimension of $150 \mathrm{~mm} \times \mathrm{x} 60 \mathrm{~mm} \times$ $6 \mathrm{~mm}$ (thickness). Aluminium oxide and Zirconium diboride particles was used as reinforcements. Groove was cut in $4 \mathrm{~mm}$ depth using EDM . The FSP unit was a vertical milling machine which has a maximum spindle speed of $1200 \mathrm{rpm}, 20$ Feed and $10 \mathrm{kN}$ force. A H13 tool with a flat shoulder mm diameter and threaded cylindrical pin of mm diameter, $\mathrm{mm}$ long was used for processing. The processing parameters for carrying out the FSP technique was optimized based on trial and error method and the tool rotating speed and feed rate was finalized to be $1200 \mathrm{rpm}$ and $15 \mathrm{~mm} / \mathrm{min} 5 \mathrm{kN}$ force respectively. Equal proportions of aluminium oxide and zirconium diboride were mixed with $250 \mathrm{ml}$ of acetone in the beaker. Then were put in magnetic pellets in to the beaker and stirred at a speed of 1560rpm and then dried. The mixture of reinforcement powder was packed into the groove of $0.3 \mathrm{~mm}$, $0.6 \mathrm{~mm}, 0.9 \mathrm{~mm}$ widths and $4 \mathrm{~mm}$ depth. The vertical milling machine was used to carry out the FSP at Vigshan tools, Coimbatore.

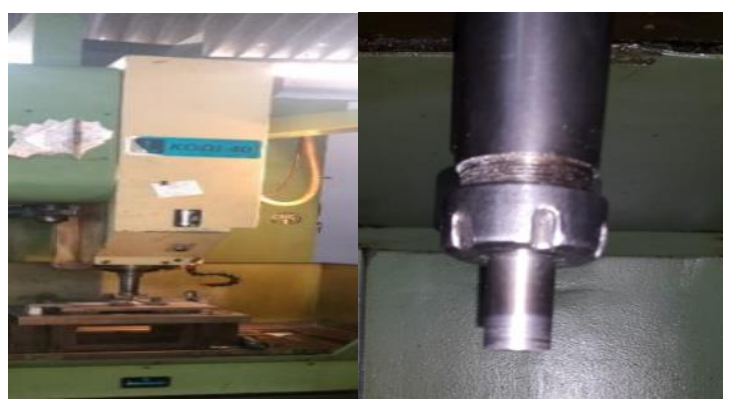

Fig. 2.A) Vertical Milling b) H13 steel tool

A typical experimental FSP setup is shown in figure 2 a). Friction Stir Processing is performed on universal milling machine. The figure $2 \mathrm{~b}$ )shows the $\mathrm{H} 13$ steel with hexagonal tool profile.Figure 3 shows that the workpiece of aluminum after completing of the friction stir processing.

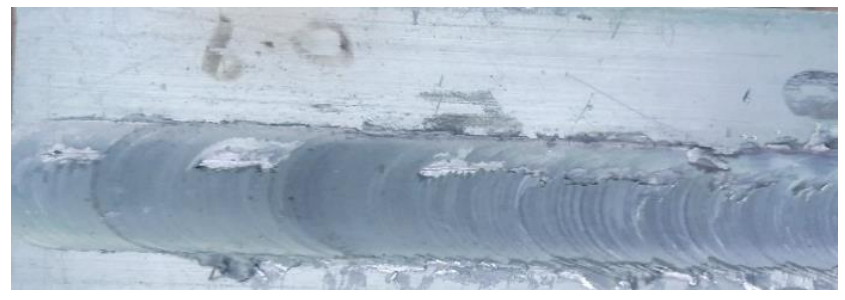

Fig. 3. Workpiece after FSP

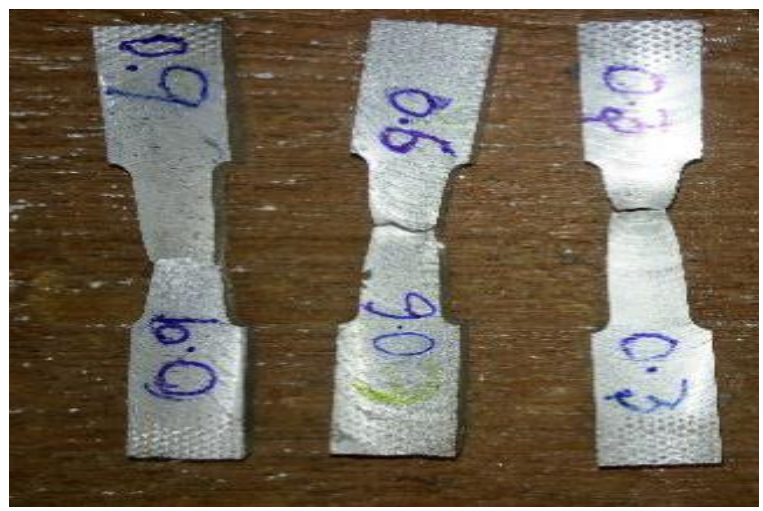

Fig. 4.Tensile specimens after test

Surface composites were fabricated successfully by friction stir processing as per the required dimension. After the friction stir processing, the specimens were cut according to the
ASTME8 standard. The tensile test was carried for 3 specimens in CRM lab, KSMS, Karunya Institute of Science and Technology. Figure 4 indicates the workpiece after completion of the tensile test.

\section{RESULTS \& DISCUSSION}

Tensile Strength Test

Figure 5 shows that Tensile strength test was conducted and we could see that the tensile strength of the composite decreases as the volume percentage of the particles added for the reinforcement increases in the composites.

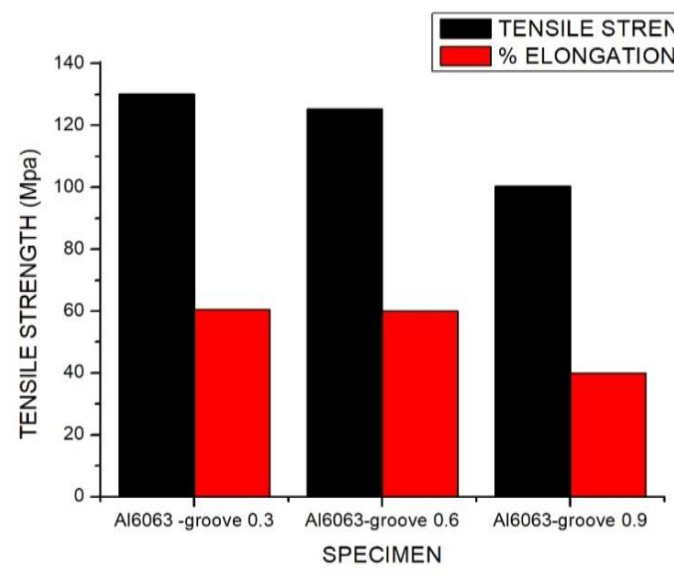

Fig. 5.Tensile strength and elongation comparison

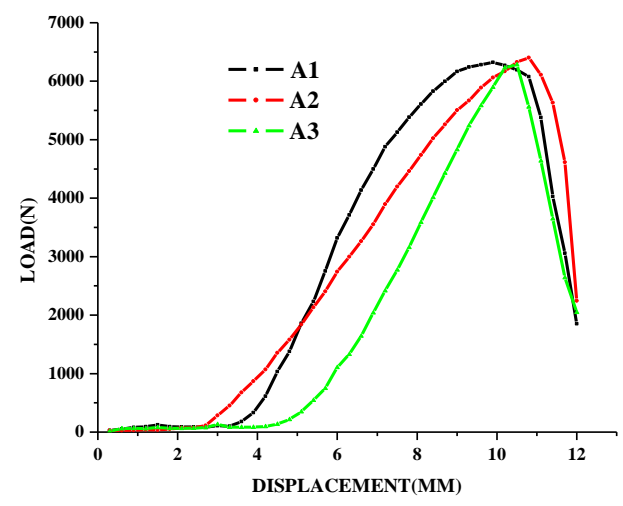

Fig. 6.Load/Displacemet curve

Figure 6 shows the trend of the stress strain curve.The ultimate yield strength of the sample 2 is more than the other two samples

\section{CONCLUSION}

Aluminium 6063 alloy reinforced with 5\%, 10\% and 15\% wt. of Zirconium diboride and Aluminium oxide particles was successfully fabricated by friction stir processing process. Tensile strength test was conducted as per ASTM E 8 standard and it is found that that the tensile strength of the composite decreases as the volume percentage of the particles added for the reinforcement increases in the composites. 


\section{REFERENCES}

1. T. Thankachan, K. S. Prakash, and V. Kavimani, 'Investigating the effects of hybrid reinforcement particles on the microstructural mechanical and tribological properties of friction stir processed copper surface composites', Compos. Part B, vol. 174, no. June, p. 107057, 2019.

2. A. Thangarasu, N. Murugan, I. Dinaharan, and S. J. Vijay, 'Synthesis and characterization of titanium carbide particulate reinforced AA6082 aluminium alloy composites via friction stir processing', Arch. Civ. Mech. Eng., vol. 15, no. 2, pp. 324-334, 2015.

3. M. Balakrishnan, I. Dinaharan, R. Palanivel, and R. Sathiskumar, 'Effect of friction stir processing on microstructure and tensile behavior of AA6061/Al 3 Fe cast aluminum matrix composites', $J$. Alloys Compd., vol. 38, no. September 2018, pp. 531-541, 2019.

4. S. J. Abraham, S. C. R. Madane, I. Dinaharan, and L. J. Baruch, 'Development of quartz particulate reinforced AA6063 aluminum matrix composites via friction stir processing', J. Asian Ceram. Soc., vol. 4, no. 4, pp. 381-389, 2016.

5. I. Dinaharan, R. Nelson, S. J. Vijay, and E. T. Akinlabi, 'Microstructure and wear characterization of aluminum matrix composites reinforced with industrial waste fly ash particulates synthesized by friction stir processing', Mater. Charact., vol. 118, pp. 149-158, 2016.

6. I. Dinaharan, S. Saravanakumar, K. Kalaiselvan, and S. Gopalakrishnan, 'Microstructure and sliding wear characterization of $\mathrm{Cu} / \mathrm{TiB} 2$ copper matrix composites fabricated via friction stir processing', Integr. Med. Res., pp. 1-9, 2017. 